Poster presentation

\title{
Myocardial $\mathbf{T}_{1}$-Mapping in chronic myocardial infarction: preliminary results of unenhanced and contrast enhanced $M R$ imaging using Gadobutrol Kerstin U Bauner*1, Andreas Biffar ${ }^{1}$, Daniel Theisen ${ }^{1}$, Torleif Sandner ${ }^{1}$, Andreas Greiser ${ }^{2}$, Maximilian F Reiser ${ }^{1}$ and Bernd Wintersperger ${ }^{1}$
}

\author{
Address: ${ }^{1}$ Ludwig-Maximilian-University Munich, Campus Grosshadern, Munich, Germany and 2Siemens Medical Solutions, Erlangen, Germany \\ * Corresponding author
}

from 13th Annual SCMR Scientific Sessions

Phoenix, AZ, USA. 21-24 January 2010

Published: 21 January 2010

Journal of Cardiovascular Magnetic Resonance 2010, I2(SuppI I):PI54 doi:I0.I 186/I532-429X-I2-SI-PI54

This abstract is available from: http://jcmr-online.com/content/I2/SI/PI54

(C) 2010 Bauner et al; licensee BioMed Central Ltd.

\section{Purpose}

At a given field strength tissues present with specific $\mathrm{T}_{1^{-}}$ values. Reference values for normal unenhanced myocardium have been established. We hypothesize, that infarcted myocardial tissue can be delineated from normal myocardium by means of $T_{1}$-maps in unenhanced and contrast-enhanced scans.

\section{Materials and methods}

13 patients with chronic myocardial infarction were examined at $1.5 \mathrm{~T}$ (Magnetom Avanto, Siemens Healthcare). A modified Look-Locker inversion recovery (MOLLI) sequence (TR/TE 200.7/1.03 msec; TI 100-4000 msec; flip $35^{\circ}$ ) was performed pre- and 10 min post-contrast $(0.15 \mathrm{mmol} / \mathrm{kg}$ gadobutrol, Bayer Schering Pharma) at an apical, midmyocardial and basal short axis position. For calculation of $\mathrm{T}_{1}$-values signal intensities of myocardial and infracted tissue were measured at 11 points of time [1]with two blocks of 3 and a third block 5 consecutive image acquisitions. Within each block TI increased by steps of $80 \mathrm{msec}$.

15 minutes after contrast medium application a single slice IR GRE was employed for imaging of delayed enhancement.

Data were post-processed with an in-house built software (PMI 0.4). $\mathrm{T}_{1}$ maps were created on the basis of unenhanced (fig. 1) and enhanced (fig. 2) data. Areas of normal and infarcted myocardial tissue were identified on delayed enhancement images and the regions of interest were copied to the unenhanced and enhanced MOLLI images. The analyses of $\mathrm{T}_{1}$-values were performed for normal myocardium (MYO), infarcted myocardium (CMI) and the left ventricular cavity (LVC). In addition T1-ratios of $\mathrm{MYO} / \mathrm{LVC}$ and $\mathrm{CMI} / \mathrm{LVC}$ were calculated.

Student's t-test was used for statistical analysis of acquired and calculated data.

\section{Results}

The comparison of $\mathrm{T}_{1}$-values of MYO (fig. 3) and CMI (fig. 4) revealed significant differences in pre-contrast scans (1028 \pm 36 vs. $1210 \pm 63$ msec; $\mathrm{p}<0.001)$, as well as CMI $\mathrm{T}_{1}$-values in comparison to $\mathrm{LVC}(1210 \pm 63 \mathrm{vs} .1509 \pm 70$ msec; $\mathrm{p}<0.001)$. The calculated ratios of MYO/LVC and $\mathrm{CMI} / \mathrm{LVC}$ were also significantly different $(0.68 \pm 0.04$ vs. $0.79 \pm 0.06 ; \mathrm{p}<0.001)$ in pre-contrast scans. In postcontrast evaluations differences of T1-values in MYO and CMI were equally high $(360 \pm 46$ vs. $224 \pm 55$ msec; p < 0.001 ) resulting in significantly different $\mathrm{T} 1$-ratios of MYO/LVC $(1.5 \pm 0.21)$ and CMI/LVC $(0.9 \pm 0.10 ; \mathrm{p}<$ $0.001)$.

\section{Conclusion}

MR-measurements of $\mathrm{T}_{1}$-values with the $\mathrm{LVC}$ as reference allow for differentiation of infarcted areas from normal myocardium. Further studies are warranted for a normalization of values in order to reduce the dependency on contrast timing, dose and agent. 


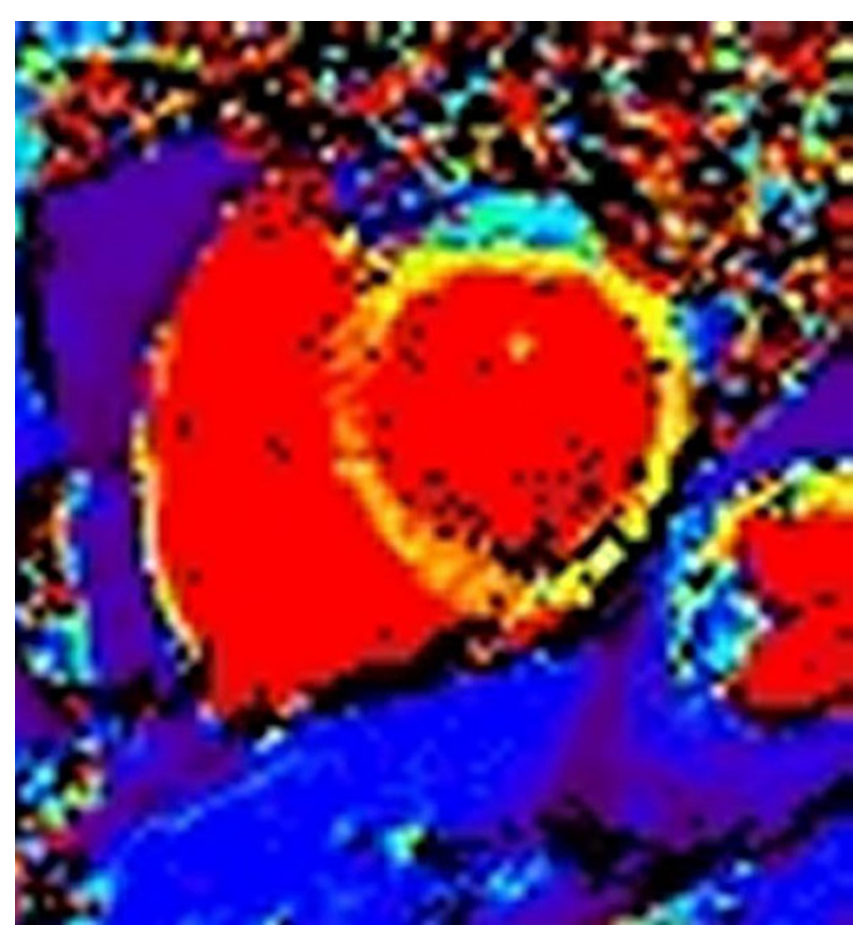

Figure I

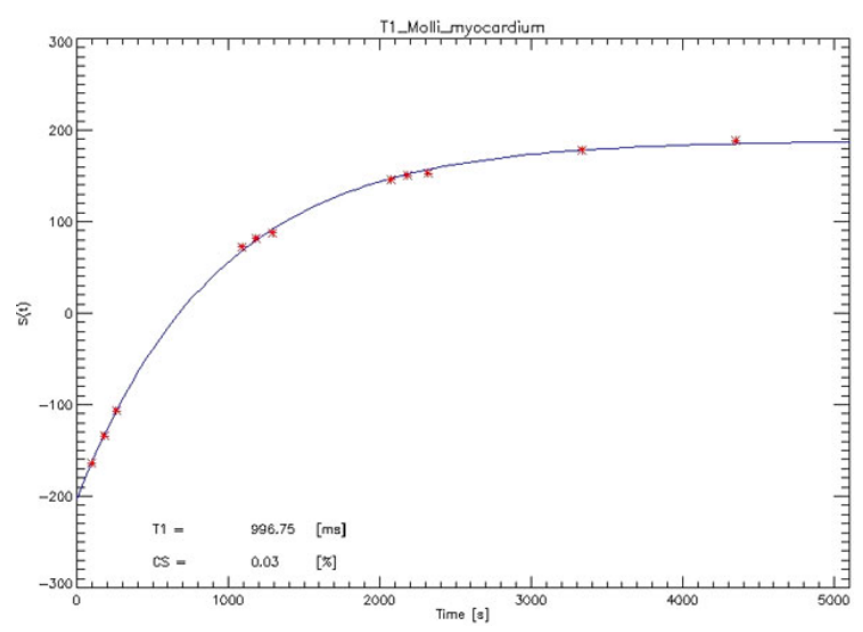

Figure 3

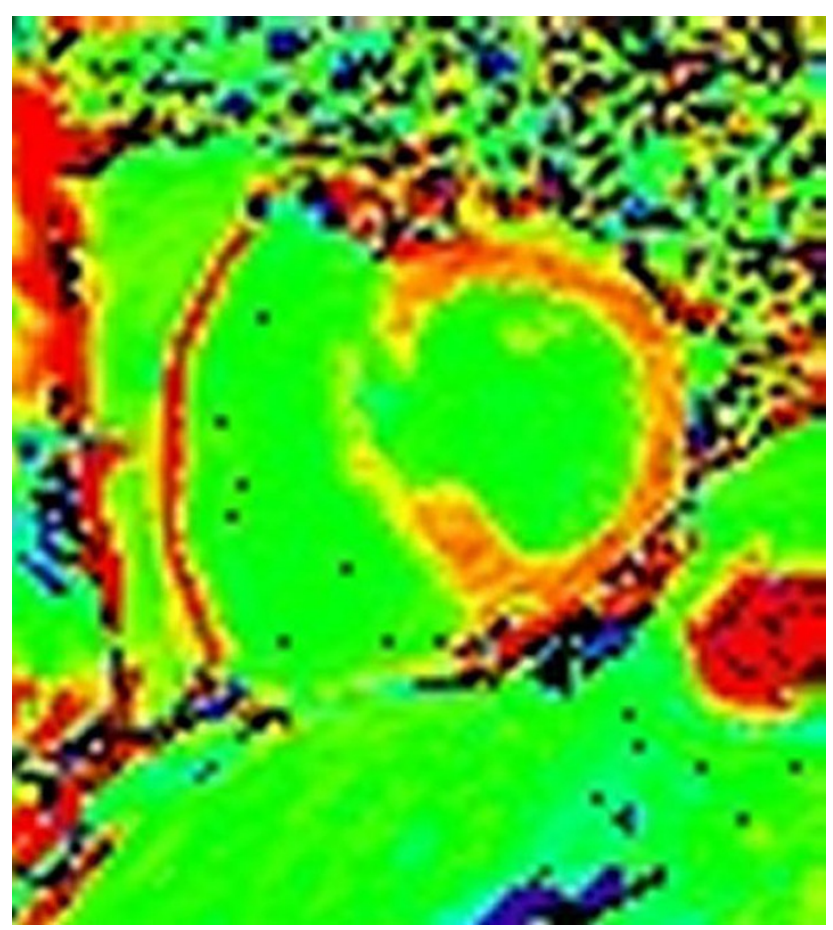

Figure 2

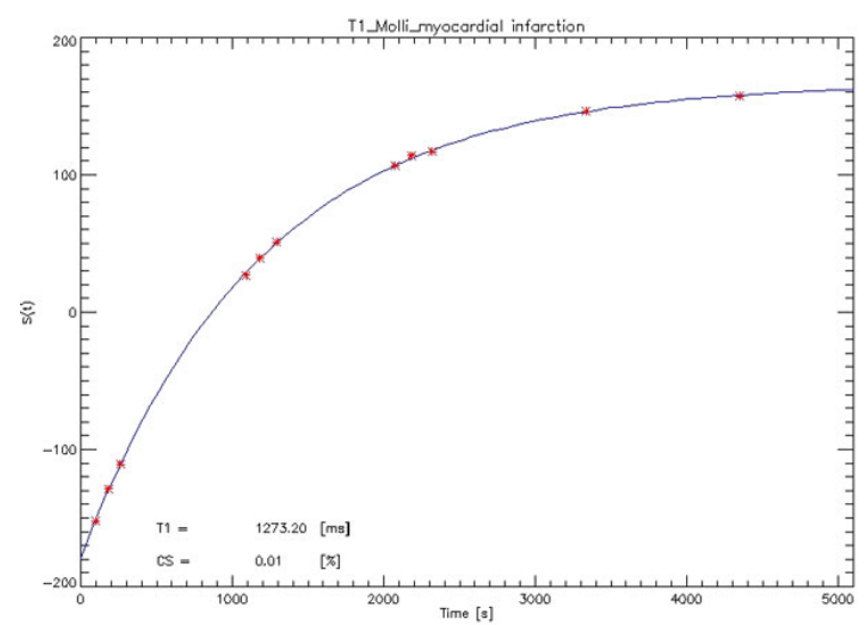

Figure 4 


\section{References}

I. Daniel Messroghli R, et al:: Optimization and Validation of a Fully-Integrated Pulse Sequence for Modified Look-Locker Inversion-Recovery (MOLLI) TI Mapping of the Heart. JMRI 2007, 26: $1081-1086$.

Publish with Bio Med Central and every scientist can read your work free of charge

"BioMed Central will be the most significant development for disseminating the results of biomedical research in our lifetime." Sir Paul Nurse, Cancer Research UK

Your research papers will be:

- available free of charge to the entire biomedical community

- peer reviewed and published immediately upon acceptance

- cited in PubMed and archived on PubMed Central

- yours - you keep the copyright 